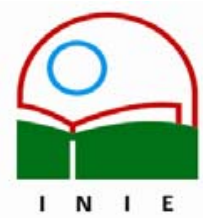

Actualidades Investigativas en Educación

Revista Electrónica publicada por el

Instituto de Investigación en Educación

Universidad de Costa Rica

ISSN 1409-4703

http://revista.inie.ucr.ac.cr

COSTA RICA

\title{
CONTENIDO Y ALCANCE DEL DERECHO A LA EDUCACIÓN EN EL
} ÁMBITO INTERNACIONAL

CONTENT AND REACH OF THE RIGHT TO AN EDUCATION IN THE INTERNATIONAL SCOPE

Volumen 7, Número 2

Mayo-Agosto 2007

pp. 1-39

Este número se publicó el 30 de agosto 2007

Alfonso Chacón Mata

La revista está indexada en los directorios:

LATINDEX, REDALYC, IRESIE, CLASE, DIALNET, DOAJ, E-REVIST@S,

La revista está incluida en los sitios:

REDIE, RINACE, OEI, MAESTROTECA, HUASCARAN 


\title{
CONTENIDO Y ALCANCE DEL DERECHO A LA EDUCACIÓN EN EL ÁMBITO INTERNACIONAL CONTENT AND REACH OF THE RIGHT TO AN EDUCATION IN THE INTERNATIONAL SCOPE
}

\author{
Alfonso Chacón Mata ${ }^{1}$
}

\begin{abstract}
Resumen: El derecho a la educación en el orden internacional ha tendido, desde mediados del siglo pasado, a ser una materia susceptible de tutelar debido a su creciente interés y necesidad. En el ámbito del sistema de la Organización de las Naciones Unidas se han diseñado pactos o tratados capaces de ser ratificados por todos los Estados miembros de la comunidad internacional, en los que se protege el derecho a la educación, señalando obligaciones positivas o de hacer, concretizar; ejecutar determinadas políticas para los Estados suscriptores. Asimismo, los mecanismos extraconvencionales de protección de los derechos humanos han establecido las Relatorías especiales, siendo la Relatoría del derecho a la educación una posibilidad de diagnosticar los alcances y desfases que se puedan presentar en la práctica. Por otra parte, el desarrollo multilateral de Conferencias Mundiales no solo con los gobiernos, sino además con otros actores de influencia dentro de los respectivos sistemas políticos (organismos no gubernamentales; activistas y académicos etc.), han ido abordando cada vez más acertadamente el fenómeno educativo en sus diferentes niveles de acción. Esta anterior preocupación nace de los efectos nugatorios y restrictivos que el derecho a la educación ha tenido al interior de muchos países -sobre todo del denominado Tercer Mundo-, por lo que se hace necesario apoyarse en la normativa jurídica internacional con la finalidad de abrir espacios de exigibilidad y respeto a este derecho. La importancia que reviste esta situación para el caso del ámbito educativo costarricense, radica en que este tipo de cobertura exógena se complementa con la protección jurídica interna, en aras de proporcionar mayores márgenes de justiciabilidad y exigibilidad del derecho que nos ocupa. En este sentido la Sala Constitucional le ha proporcionado a los instrumentos internacionales de derechos humanos suscritos por el país, rango superior por encima de la misma Constitución Política y por consiguiente, se abre un espacio propicio para apoyarnos en esta normativa internacional con mucha mayor propiedad.
\end{abstract}

Palabras clave: DERECHO A LA EDUCACIÓN/ PACTOS Y DECLARACIONES INTERNACIONALES/ CONFERENCIA MUNDIAL DE EDUCACIÓN/ CARACTERÍSTICAS DE LA EDUCACIÓN/ OBLIGACIONES INTERNACIONALES DEL ESTADO / JUSTICIABILIDAD DEL DERECHO A LA EDUCACIÓN/

\begin{abstract}
The right to an education in the international scope has tended, ever since the middle of last century, to receive a greater attention and care; due to its increased interest and necessity. Within the limits of the UN's system, pacts and treaties with the capability of ratification by all the member States in the international community have been designed; under said treaties the right to an education has been protected, pointing at positive obligations, or obligations towards the making, realization and execution of specific policies for the enrolled States. Also, the means beyond conventional practice for the protection of human rights have established the special Rapporteurs, being the Rapporteur of the right to an education a possibility for diagnosing the possibilities and gaps that may happen in the practice. On the other hand, the multilateral development of World Conferences not only with governments, but with others influential actors within the proper political systems as well (non-governmental organizations, activists and academics, etc.) has been dealing with increasing success with the educative phenomenon in its different levels of action. This prior concern is born from the nullifying and restrictive effects suffered by the right to an education inside many countries-especially for the so-dubbed Third World-, thus taking support on the international legal rulings becomes a necessity, with the finality of opening spaces for the demand and respect to this right. The importance of this situation in the field of Costa Rican education lies on the fact that this coverage from external sources is complemented with the internal protection of the law, with the interest of creating greater margins for the successful execution of justice and the rights discussed in this text. In this sense, the Constitutional Court has granted the international instruments of human rights that include the country a rank beyond the level of the very same Constitution; and thus, an auspicious space to support this international ruling with greater propriety is opened.
\end{abstract}

Keywords: THE RIGHT TO AN EDUCATION/ INTERNATIONAL AGREEMENTS AND DECLARATIONS/ WORLD CONFERENCE ON EDUCATION/ FEATURES OF EDUCATION/ INTERNATIONAL DUTIES OF THE STATE/ APPLICATION OF JUSTICE FOR THE RIGHT TO AN EDUCATION

1. Máster en Derecho del Trabajo y la Seguridad Social, Universidad Estatal a
Distancia, Licenciado en Derecho de la Universidad de Costa Rica, Bachiller en
Relaciones Internacionales Internacionales de la Universidad Nacional, Costa Rica.
Diplomado en Derecho Internacional de los Derechos Humanos
de la Universidad Alcalá de Henares, España. Se ha desempeñado como
consultor en derechos humanos y laborales para el Programa
de Normas Internacionales de la Organización Internacional del Trabajo, la
Fundación para
Profesor el universitario y asesor jurídico de organizaciones laborales

vinculadas al Magisterio Nacional.

Correo electrónico: achaconm@yahoo.com

Artículo recibido: 7 de junio, 2007

Aprobado: 28 de agosto, 2007 


\section{Introducción}

El artículo que nos ocupa en esta oportunidad pretende complementar lo que hemos venido abordando anteriormente a través de este mismo espacio, como sería el caso de la justiciabilidad de los derechos económicos, sociales y culturales, siendo el derecho a la educación un componente de este ordinal de derechos (Chacón, 2006). Sin embargo, en esta oportunidad nos interesa realizar un breve recuento de los mecanismos y provisiones existentes a nivel internacional en materia de tutela del derecho a la educación. Es así como hablaremos de la definición del citado derecho en instrumentos tales como la "Declaración Universal de Derechos Humanos" y el "Pacto Internacional de Derechos Económicos, Sociales y Culturales"; o el análisis realizado por el Comité de Derechos Económicos, Sociales y Culturales del artículo 13 de este tratado, entre otras temáticas por abordar.

También haremos mención de una convención diseñada por la Organización de las Naciones Unidas (ONU) para evitar los problemas discriminatorios en la educación, así como lo que se ha dicho sobre esta materia en diferentes Conferencias Mundiales de diferente índole, como la de derechos humanos realizada en Viena (1993); la de la mujer de Beijing (1995) o la de población celebrada en el Cairo (1996), solo para citar algunas que se van a referenciar a lo largo de este trabajo.

Este recorrido retrospectivo tiene, para los efectos del sistema educativo costarricense, la importancia de reseñar diferentes vías en el ámbito jurisdiccional capaces de defender y reivindicar la legítima garantía que tiene nuestra población de recibir adecuada instrucción en diferentes niveles. Por ello resulta conveniente apostar a las disposiciones establecidas en diferentes tratados internacionales, así como a las distintas conferencias, debido a que los primeros generan obligaciones que deben ser cumplidas por parte de los Estados suscriptores y además, los foros multilaterales producen una serie de principios que constituyen fuentes de derecho internacional. Concretamente, para el caso de nuestro ámbito jurídico, tenemos que el artículo sétimo de la Constitución Política establece que los tratados internacionales debidamente ratificados por Costa Rica, son de acatamiento y de mayor jerarquía que una ley ordinaria o común. La vigencia y realce de los tratados internacionales en materia de derechos humanos -como sería el caso del derecho humano a la educación- ya ha sido dictaminado por la Sala Constitucional de la Corte Suprema de Justicia. Mediante Voto N²313-95 de las 16:18 horas del 9 de agosto de 1995, este órgano jurisdiccional estableció para los efectos conducentes lo siguiente: 
Sobre esto debe agregarse que en tratándose de instrumentos internacionales de derechos humanos vigentes en el país, no se aplica lo dispuesto por el artículo 7 de la Constitución Política, ya que el 48 constitucional tiene norma especial para lo que se refiere a derechos humanos, otorgándoles una fuerza normativa del propio nivel constitucional. Al punto que, como lo ha reconocido la jurisprudencia de esta Sala, los instrumentos de derechos humanos vigentes en Costa Rica, tienen no solamente un valor similar a la Constitución Política, sino que en la medida que otorguen mayores derechos o garantías a las personas, privan sobre la Constitución. (ÉNFASIS NUESTRO)

Lo anteriormente expuesto es aplicable a todos los convenios o pactos internacionales de derechos humanos, que tengan plena vigencia dentro de la jurisdicción costarricense. Es decir, tendrán rango prioritario o de supremacía incluso sobre el mismo texto constitucional, siempre y cuando dimensionen en mejor forma un derecho o garantía específica a tutelar. Tenemos entonces que a través de una interpretación jurisprudencial se le estarían otorgando a tales instrumentos de protección de los derechos humanos un carácter o valor supraconstitucional -mayor incluso que la Constitución Política nacional-. La importancia de esta prerrogativa consiste en que lo establecido en el pacto o tratado internacional debidamente ratificado por Costa Rica puede servir como un parámetro a ser invocado con la finalidad de salvaguardar el derecho a la educación, si a nivel interno la cobertura del derecho resultare ser menor a lo establecido en el convenio.

En razón de lo dicho, se hace imperativo que los educadores y las educadoras tengan conocimiento de estas disposiciones, en aras de obtener un empoderamiento preciso de aquellas garantías que dimensionarán el ejercicio del derecho en cuestión. Por consiguiente, procedemos a realizar un rápido recuento de las provisiones insertas a nivel de tratados de derecho internacional de los derechos humanos, en las que se dimensiona y tutela el derecho a la educación.

\section{El derecho a la Educación en el entorno internacional}

Nos interesa enfocar cuáles son los tratados suscritos dentro de la comunidad internacional, en los que se tutela específicamente la educación como tal. Por ello abordaremos los artículos 26 y 13 de la Declaración Universal de los Derechos Humanos (DHDH) y del Pacto Internacional de Derechos Económicos, Sociales y Culturales (PIDESC), respectivamente, como normativas concretas que regulan esta materia. De igual manera, la 
Convención relativa a la lucha contra las discriminaciones en la esfera de la enseñanza, contiene disposiciones importantes que consideramos dignas de mencionar. Mencionaremos finalmente de la labor de la Relatoría especial del derecho a la educación, gestada en el marco del sistema de las Naciones Unidas como una importante iniciativa de control y recomendación de mejora de la educación en sus vertientes cualitativas y cuantitativas.

\subsection{El derecho a la educación en el artículo 26 de la DHDH.}

El artículo 26 de esta Declaración Universal de Derechos Humanos, dispone lo que transcribimos a continuación:

1. Toda persona tiene derecho a la educación. La educación debe ser gratuita, al menos en lo concerniente a la instrucción elemental y fundamental. La instrucción elemental será obligatoria. La instrucción técnica y profesional habrá de ser generalizada; el acceso a los estudios superiores será igual para todos, en función de los méritos respectivos.

2. La educación tendrá por objeto el pleno desarrollo de la personalidad humana y el fortalecimiento del respeto a los derechos humanos y a las libertades fundamentales; favorecerá la comprensión, la tolerancia y la amistad entre todas las naciones y todos los grupos étnicos o religiosos; y promoverá el desarrollo de las actividades de las Naciones Unidas para el mantenimiento de la paz.

3. Los padres tendrán derecho preferente a escoger el tipo de educación que habrá de darse a sus hijos.

En torno a lo expuesto sobre la educación en la Declaración, un grupo de autores han dicho que:

Es interesante notar, que el derecho a la educación, no llegó simplemente a ser enumerado por la Declaración, sino que es efectivamente desarrollado por la misma, aspecto meritorio, para una regulación de tan alto nivel. Es decir, aun antes, de la creación del pacto internacional sobre derechos económicos, sociales y culturales, ya se encontraba mundialmente reconocida la consciente importancia de la educación. (Farrier Brais y otros, 1988, p. 1334)

El párrafo primero del supracitado artículo destaca dos situaciones que nos interesa reseñar: la gratuidad de la instrucción elemental y fundamental, y el acceso a estudios superiores en función de los méritos de cada cual. Sobre el primer punto se ha expuesto que:

Volumen 7, Número 2, Año 2007, ISSN 1409-4703 
El otro principio establecido por la Declaración que garantiza el ejercicio real del derecho, es la GRATUIDAD, sin ella, la educación se convierte no en un instrumento para el conocimiento, sino en conocimiento selectivo.

Los parámetros no son la capacidad, sino la preponderancia económica de los particulares. Esto analizado en sus últimas consecuencias, rompe con el sistema democrático al dar como consecuencia, el provecho social para unos pocos, se priva de la maximización de su potencial a personas cuyo caudal podría aportar mucho más a la sociedad (...)

La educación gratuita en lo elemental y fundamental es el principio mismo del conocimiento mínimo del hombre, para llevar a ser hombre, o para que tenga los instrumentos necesarios para llegar a serlo, sin ello, el hombre es Ausente del Mundo, y por lo tanto ausente en el mundo, soledad, tinieblas, impotencia (Maheu, René). (Farrier Brais y otros, 1988, pp. 1135-1136).

Con respecto a la educación superior, nos encontramos que la variable para llegar a esta no va a ser la capacidad netamente económica, sino la capacidad intelectual de las personas. Sin embargo, si analizamos la posibilidad de acceder a un sistema superior en nuestros tiempos, nos encontramos con la disyuntiva existente entre la limitación de presupuesto para las universidades y la creciente población estudiantil que desea cursar estudios superiores.

El segundo párrafo destaca la forma en que la educación debe canalizarse hacia dos ámbitos complementarios y nunca excluyentes: el individual y el colectivo. El primero tiende al "desarrollo de la persona humana...", desde una óptica de respeto adecuado a los derechos humanos y libertades fundamentales. El segundo ámbito apela a que la educación servirá como vehículo para "favorecer la comprensión, la tolerancia y amistad entre los grupos étnicos y religiosos", toda vez que se debe acompañar con una efectiva cultura de la paz $^{2}$.

Por último, se hace mención a la libertad de enseñanza que pueden emplear los padres a la hora de escoger el tipo de educación que recibirán sus hijos e hijas: ya sea privada o pública, lo cual no es un ámbito en el que los Estados deban interferir. Obviamente, tratándose de sectores marginados económica y socialmente, la educación pública se constituye en una panacea de avance y movilidad de primer orden, por lo que esta función estatal en dicho campo debe entenderse como de índole proyectiva y expansiva, creando oportunidades para quienes necesiten acceder al sistema de educación formal y 
hasta técnica, sin tener recelo a ser excluidos por no poder pagar los aranceles o importes de matrícula.

\subsection{El derecho a la educación en el artículo 13 PIDESC.}

El Pacto Internacional de Derechos Económicos, Sociales y Culturales (PIDESC) entró en vigencia casi veinte años después que se adoptara la Declaración Universal -se aprueba en el año 1966 en el marco de la Conferencia de Teherán-. Por consiguiente, se retoman necesariamente una serie de principios insertos de previo en la DUDH, los cuales sirven de antecedente.

El párrafo primero aduce, con algunos ligeros cambios, lo expuesto en el párrafo segundo del artículo 26 de la Declaración Universal señalado anteriormente. Se establecen algunos cambios como el de acotar que la educación debe orientarse hacia el sentido de la "dignidad personal", y enumera que la educación "debe capacitar a todas las personas para participar efectivamente en una sociedad libre"3.

Tenemos que el párrafo segundo se refiere a la manera como debe implementarse el ejercicio del derecho a la educación. En este punto nos interesa destacar la forma en que se segmentan los diferentes tipos de enseñanza y como deben implementarse por los respectivos Estados adoptantes del convenio. Así tenemos que se describen cuatro incisos claves que detallamos a continuación:

Con respecto a la enseñanza primaria, esta "debe ser obligatoria y asequible a todos gratuitamente" (inciso a). A su vez, se visualiza a la enseñanza secundaria en sus diferentes formas, contemplándose la secundaria técnica y profesional; y por ello se aduce que "debe ser generalizada". Nos encontramos con que este último tipo de enseñanza, se subordina en su accesibilidad por "...la implementación progresiva de la enseñanza gratuita" (inciso b).

Se habla de tener

...en la medida de lo posible", una educación fundamental para aquellas personas que no hayan recibido o tomado el ciclo completo de instrucción primaria. Esta es la educación de adultos y los diferentes programas encaminados a alfabetizar y educar a aquellas personas mayores, que por uno u otro motivo no hayan podido cursar este tipo de enseñanza (inciso d). Al final, la norma llama a una serie de aspiraciones o tareas específicas: desarrollar activamente el sistema escolar en todos los ciclos de enseñanza; implementar un sistema adecuado de becas y mejorar continuamente las condiciones materiales del cuerpo docente (inciso e). 
Sobre la naturaleza del derecho a la educación tutelado en este instrumento internacional, los especialistas han dicho que "El derecho a la educación, reconocido en los artículos 13 y 14 del Pacto, así como en otros tratados internacionales, tales como la Convención sobre los Derechos del Niño y la Convención sobre la eliminación de todas las formas de discriminación contra la mujer, es de vital importancia. Se ha clasificado de distinta manera como derecho económico, derecho social y derecho cultural. Es, todos esos derechos al mismo tiempo. También, de muchas formas, es un derecho civil y un derecho político, ya que se sitúa en el centro de la realización plena y eficaz de esos derechos. A este respecto, el derecho a la educación es el epítome de la indivisibilidad y la Interdependencia de todos los derechos humanos. (Círculo de Derechos, p. 353).

\subsection{Observación General № 13 del Comité de Derechos Económicos, Sociales y Culturales de la ONU: "El Derecho a la Educación (artículo 13 del Pacto Internacional de Derechos Económicos, Sociales y Culturales)}

En el marco del vigésimo período de sesiones del Comité de Derechos Económicos, Sociales y Culturales realizado en el año 1999, se emitió la observación general número 13, denominada El derecho a la educación. Empieza advirtiendo el párrafo primero que

1. La educación es un derecho humano intrínseco y un medio indispensable de realizar otros derechos humanos. Como derecho del ámbito de la autonomía de la persona, la educación es el principal medio que permite a adultos y menores marginados económica y socialmente salir de la pobreza y participar plenamente en sus comunidades. La educación desempeña un papel decisivo en la emancipación de la mujer, la protección de los niños contra la explotación laboral, el trabajo peligroso y la explotación sexual, la promoción de los derechos humanos y la democracia, la protección del medio ambiente y el control del crecimiento demográfico. Está cada vez más aceptada la idea de que la educación es una de las mejores inversiones financieras que los Estados pueden hacer, pero su importancia no es únicamente práctica pues dispone de una mente instruida, inteligente y activa, con libertad y amplitud de pensamiento, es uno de los placeres y recompensas de la existencia humana. (ONU, 2001, p. 82)

En relación con la dimensión jurídica del artículo 13 del PIDESC, el citado comité aduce que 
Los Estados Partes convienen en que toda la enseñanza, ya sea pública o privada, escolar o extraescolar, debe orientarse hacia los propósitos y objetivos que se definen en el párrafo 1 del artículo 13. El Comité observa que estos objetivos de la educación reflejan los propósitos y principios fundamentales de las Naciones Unidas, consagrados en los Artículos 1 y 2 de la Carta. Se encuentran asimismo, en su mayor parte, en el párrafo 2 del artículo 26 de la Declaración Universal de Derechos Humanos, si bien el párrafo 1 del artículo 13 amplía la Declaración desde tres puntos de vista: la educación debe orientarse al desarrollo del sentido de la dignidad de la personalidad humana, debe capacitar a todas las personas para participar efectivamente en una sociedad libre y debe favorecer la comprensión entre todos los grupos étnicos, y entre las naciones y los grupos raciales y religiosos. De todos esos objetivos de la educación que son comunes al párrafo 2 del artículo 26 de la Declaración Universal de Derechos Humanos y al párrafo 1 del artículo 13 del Pacto, acaso el fundamental sea el que afirma que "la educación debe orientarse hacia el pleno desarrollo de la personalidad humana.

\subsubsection{Apartado (b) del párrafo 2 del artículo 13 -El derecho a la enseñanza} secundaria-

La enseñanza secundaria comprende los elementos de disponibilidad, accesibilidad, aceptabilidad y adaptabilidad que son comunes a la enseñanza en todas sus formas y en todos sus niveles y la "implantación progresiva de la enseñanza gratuita" significa que, si bien los Estados deben atender prioritariamente a la enseñanza primaria gratuita, también tienen la obligación de adoptar medidas concretas para implantar la enseñanza secundaria y superior gratuitas (Círculo de Derechos, p. 356). Aduce el párrafo decimotercero lo siguiente: "De conformidad con el apartado b) del párrafo 2 del artículo 13, la enseñanza secundaria debe "ser generalizada y hacerse accesible a todos, por cuantos medios sean apropiados, y en particular por la implantación progresiva de la enseñanza gratuita". La expresión "generalizada" significa, en primer lugar, que la enseñanza secundaria no depende de la aptitud o idoneidad aparentes de un alumno y en segundo lugar, que se impartirá en todo el Estado de forma tal que todos puedan acceder a ella en igualdad de condiciones (ONU, 2001, p. 86).

Ahora bien, sobre el valor de la educación especializada/técnica, en la Declaración Universal de Derechos Humanos se afirma que "la instrucción técnica y profesional habrá de 
ser generalizada". De acuerdo con la observación general que estamos escudriñando, el derecho a la enseñanza técnica y profesional abarca los siguientes aspectos:

a) Capacita a los estudiantes para adquirir conocimientos y competencias que contribuyan a su desarrollo personal, su posibilidad de valerse por sí mismos y acrecienta la productividad de sus familias y comunidades, comprendido el desarrollo social y económico del Estado Parte;

b) Tiene en cuenta las circunstancias sociales, culturales y educativas de la población en cuestión; las competencias, los conocimientos y los niveles de calificación necesarios en los diversos sectores de la economía; y el bienestar, la higiene y la seguridad laborales;

c) Se ocupa de reciclar a los adultos cuyos conocimientos y competencias hayan quedado atrasados a causa de las transformaciones tecnológicas, económicas, laborales, sociales, etc;

d) Consiste en programas que den a los estudiantes, especialmente a los de los países en desarrollo, a la posibilidad de recibir enseñanza técnica y profesional en otros Estados, con vistas a una transferencia y una adaptación de tecnologías correctas. (ONU: 2001, p.82)

\subsubsection{Apartado (c) del párrafo 2 del artículo 13 -El derecho a la enseñanza superior-}

La enseñanza superior comprende igualmente los elementos de disponibilidad, accesibilidad, aceptabilidad y adaptabilidad, que son comunes a la enseñanza en todas sus formas y que hemos reseñado anteriormente. Sin embargo, según el apartado (c) del párrafo 2 del artículo 13, la enseñanza superior no "debe ser generalizada", sino solo disponible "sobre la base de la capacidad", capacidad que habrá de valorarse con respecto a los conocimientos especializados. El párrafo 14 de la observación general que nos ocupa, aduce que "La implantación progresiva de la enseñanza gratuita" significa que, si bien los Estados deben atender prioritariamente a la enseñanza primaria gratuita, también tienen la obligación de adoptar medidas concretas para implantar la enseñanza secundaria y superior gratuitas" (ONU, 2001, p.88).

Por último, sobre la educación fundamental tenemos que el documento en análisis estima que todos tienen el derecho de satisfacer sus "necesidades básicas de aprendizaje", por lo que el derecho a la educación fundamental no se limita a quienes "no hayan recibido o terminado el ciclo completo de instrucción primaria" y apuesta a un estándar más integral y 
completo: El derecho a la educación fundamental se aplica a todos los que todavía no han satisfecho sus "necesidades básicas de aprendizaje" (ONU, 2001, p.87).

\subsection{Convención Relativa a la Lucha contra las Discriminaciones en la Esfera de la Enseñanza.}

Tenemos como tesis inicial que la intolerancia y la discriminación se constituyen, en cualquier forma en que aparezcan, como los obstáculos que impiden la existencia de igualdad real y no solamente formal o jurídica, entre todos los seres humanos (Odio, 1990, p.196). La Asamblea General de la ONU, aprobó la presente convención el 14 de diciembre de 1960, que reza en su artículo primero, lo que transcribimos seguidamente:

1. A los efectos de la presente Convención, se entiende por discriminación toda distinción, exclusión, limitación con preferencia, fundada en la raza, el color, el sexo, el idioma, la religión, las opiniones políticas o de cualquier otra índole, el origen nacional o social, la posición económica o el nacimiento, que tenga por finalidad o por efecto destruir o alterar la igualdad de trato en la esfera de la enseñanza y, en especial:

a) Excluir a una persona o a un grupo del acceso a los diversos grados y tipos de enseñanza;

b) Limitar a un nivel inferior la educación de una persona o de un grupo;

c) Instituir o mantener sistemas o establecimientos de enseñanzas separados para personas o grupos;

d) Colocar a una persona o a un grupo en una situación incompatible con la dignidad humana.

El mismo instrumento establece, por su parte, una serie de acciones encaminadas a prevenir y eliminar la discriminación en su artículo tercero, tales como derogar disposiciones legislativas y administrativas y abandonar todas las prácticas administrativas que entrañen discriminaciones en la esfera de la enseñanza, o adoptar las medidas necesarias, inclusive disposiciones legislativas, para que no se haga discriminación alguna en la admisión de los alumnos en los establecimientos de enseñanza, no hacer ninguna distinción en concesiones como becas o ayuda para los niños y niñas entre nacionales y extranjeros.

Este instrumento internacional se torna bastante interesante, puesto que en primer lugar nos define las diferentes modalidades de discriminación sobre las que se puede fundar la exclusión del derecho a la enseñanza y, en segundo lugar, impone una gama de 
obligaciones de diferente índole a los Estados suscriptores para evitar esta práctica. Es así como nos encontramos obligaciones tanto positivas - de hacer- como de naturaleza negativa -o de no hacer-, con la finalidad de salvaguardar el derecho a no recibir discriminación en el fuero educativo. Los suscriptores adquieren un compromiso de primer orden con este convenio, y estimamos que ha sido poco explotado en sus provisiones y alcances.

Un aspecto que es sumamente importante aclarar es el concerniente al "Protocolo por el que se instituye una Comisión de Conciliación y Buenos Oficios facultada para resolver las controversias que puedan plantearse entre Estados Partes en la Convención relativa a la Lucha contra las Discriminaciones en la Esfera de la Enseñanza". Este instrumento se estatuye en París el 10 de diciembre de 1962 y como paso trascendental crea la Comisión antes señalada. Esta instancia, de acuerdo con el artículo segundo "...se compondrá de once miembros, que habrán de ser personalidades conocidas por su elevada moralidad y su imparcialidad, y serán elegidos por la Conferencia General de la Organización de las Naciones Unidas para la Educación, la Ciencia y la Cultura, que se denominará en adelante la Conferencia General". Por otra parte, los miembros son elegidos por un período de seis años con posibilidad de reelección en sus cargos.

Una de las novedades de este instrumento, radica en que los Estados suscriptores pueden denunciarse entre sí, con la finalidad de exigirse el cumplimiento de las prerrogativas insertas dentro del tratado marco o convención. Es así como el artículo doceavo enuncia un procedimiento consistente en lo siguiente: a) Si un Estado Parte en el presente Protocolo estimare que otro Estado también Parte en este Protocolo no aplica las disposiciones de la Convención, podrá señalar el hecho a la atención de ese Estado mediante comunicación escrita. Dentro del plazo de tres meses, contados a partir del recibo de la comunicación, el Estado destinatario comunicará por escrito al Estado que haya presentado la queja explicaciones o declaraciones que deberán contener, en toda la medida de lo posible y conveniente, indicaciones sobre sus normas procesales y sobre los recursos interpuestos, en tramitación; b) Si, seis meses después de la fecha en que el Estado destinatario hubiere recibido la comunicación original, no estuviere resuelto el asunto a satisfacción de los dos Estados, sea por negociaciones bilaterales, o por cualquier otro procedimiento que puedan utilizar, tanto con uno como el otro tendrá derecho a someterla a la Comisión, dirigiendo una comunicación al Director General y al otro Estado interesado.

Finalmente contempla la posibilidad de someter el conflicto a otros procedimientos de solución de controversias, paralelos al que se describe en el Protocolo; incluso de acudir a 
la Corte Permanente de Arbitraje de La Haya. Podría pensarse que lo trascendental de esta disposición es que aparte de las denuncias individuales tradicionalmente generalizadas a todos los mecanismos convencionales de derechos humanos derivados de los tratados sean comités tales como el Comité de Derechos Humanos establecido en el Pacto Internacional de Derechos Civiles y Políticos; el Comité de Discriminación Racial establecido el la Convención contra todas las formas de Discriminación Racial, entre otros-, en esta oportunidad se concibe otro mecanismo totalmente distinto, sin embargo este procedimiento igualmente tiene sus bemoles. En primer lugar, la conciliación es entre Estados, por lo que muy difícilmente se suscite la posibilidad que dos colectividades estatales diriman una controversia como la que nos ocupa, debido al principio de soberanía y aceptación de la renuncia a la jurisdicción propia. Segundo, como una consecuencia derivada de lo anteriormente expuesto, los particulares no podrían denunciar a los Estados a través de este protocolo de arbitraje, y en consecuencia, se desnaturaliza completamente la posibilidad de acceder individualmente a este mecanismo.

Por las razones expuestas estimo que el procedimiento se vuelve muy restrictivo y poco generalizado, cercenando su verdadera dimensión de conseguir una justiciabilidad plena del derecho a la no discriminación educativa. A manera de comentario final, según reza el artículo 13 del protocolo en estudio, es posible ejercer por parte de la Comisión una función de mediadora entre los Estados si así lo consintieren expresamente. Finalmente, se habla del sistema de control a través de la elaboración de informes, que se sometería al Director General de la UNESCO, quien los haría eventualmente de conocimiento de la Asamblea General.

\subsection{Convención de los Derechos del Niño (1989)}

La gestación de la Convención de Derechos del Niño, tiene como base las resoluciones 33/166, de 20 de diciembre de 1978, y 43/112, de 8 de diciembre de 1988, todas de la Asamblea General. Asimismo, fueron claves en todo este proceso la resolución 1989/57, de 8 de marzo de 1989 de la Comisión de Derechos Humanos, por lo que la Comisión decidió transmitir a la Asamblea General, por conducto del Consejo Económico y Social, el proyecto de convención sobre los derechos del niño y la resolución de 1989/79 del Consejo Económico y Social, de 24 de mayo de 1989. Finalmente la convención fue adoptada y abierta a la firma y ratificación por la Asamblea General en su resolución 44/25, de 20 de noviembre de 1989, entrando en vigor en menos de un año -el 2 de septiembre de 
1990-, de conformidad con el artículo 49, que exige para el vigor de este tratado al menos veinte ratificaciones o adhesiones.

Por primera vez en la historia del Derecho Internacional, los derechos de la niñez son incorporados en un tratado que tendrá fuerza coercitiva para todos aquellos Estados que los ratifiquen, a diferencia de la Declaración de 1959, que se quedaba en tan solo una carta de buenas intenciones. Al mismo tiempo, sus normas engrosarán progresivamente el derecho consuetudinario de los derechos de la niñez. Con la Convención sobre los Derechos del Niño se abandonó la antigua doctrina de la situación irregular ${ }^{4}$, que consideraba a los niños y a las niñas incapaces de asumir responsabilidad por sus acciones. Esta Convención, junto con otros instrumentos internacionales, acogió la doctrina de la protección integral, que reconoce al infante su condición de sujeto de derecho y le confiere un papel principal en la construcción de su propio destino. En materia penal, específicamente, significó el cambio de una jurisdicción tutelar a una punitivo-garantista, en la cual, entre otras medidas, se reconocen plenamente los derechos y garantías de los niños y de las niñas; se les considera responsables de sus actos delictivos; se limita la intervención de la justicia penal al mínimo indispensable; se amplía la gama de sanciones, basadas en principios educativos; y se reduce al máximo la aplicación de las penas privativas de la libertad.

La Convención sobre los Derechos del Niño, entre otros instrumentos internacionales, y la elaboración de la doctrina de la protección integral trajeron consigo el surgimiento del Derecho de los niños como una nueva rama jurídica, basada en tres pilares fundamentales: el interés superior del niño, entendido como la premisa bajo la cual se debe interpretar, integrar y aplicar la normativa de la niñez y la adolescencia, y que constituye, por ello, un límite a la discrecionalidad de las autoridades en la adopción de decisiones relacionadas con los niños y las niñas; el menor de edad como sujeto de derecho, de manera que se reconocen a éste, tanto los derechos humanos básicos como los que sean propios de su condición de infante; y el ejercicio de los derechos fundamentales y su vínculo a la autoridad parental: siendo que la autoridad parental tiene como único fin procurar al niño la protección y los cuidados indispensables para garantizar su desarrollo integral, constituye una responsabilidad y un derecho para los padres, pero también un derecho fundamental para los niños a ser protegidos y orientados hasta alcanzar su plena autonomía. Por ello, el ejercicio de autoridad debe disminuir conforme avanza la edad del niño.

Hemos sentido la necesidad de destacar este instrumento internacional, debido a que con relación con el derecho a la educación, indudablemente se establecen una serie de prácticas a observar por parte de los Estados partes, con la finalidad de tutelar y privilegiar 
que los menores tengan acceso a este beneficio. El tratado presenta la particularidad de que con la finalidad de examinar los progresos realizados en el cumplimiento de las obligaciones contraídas por los Estados Parte, se delegará esta función al Comité de los Derechos del Niño a través del sistema de informes. Este Comité estará integrado por diez expertos de gran integridad moral y reconocida competencia de los derechos de la niñez. El informe sobre las medidas que hayan adoptado para dar efecto a los Derechos reconocidos en la Convención y sobre el progreso en cuanto al goce de esos derechos, debe ser presentado a los dos años a partir de la fecha en la que para cada Estado Parte haya entrado en vigor la Convención. Posteriormente se presentará cada cinco años. En estos informes se deberá indicar las circunstancias y dificultades, si las hubiere, que afecten el cumplimiento de las obligaciones derivadas de la Convención. Deberá contener toda la información suficiente para que el Comité tenga cabal comprensión en el país de que se trate. Este Comité informará cada dos años de la Asamblea General de la ONU sobre sus actividades y podrá pedir a los Estados Parte más información relativa a la aplicación de la Convención.

Además del informe gubernamental, el Comité recibe información sobre la situación de los derechos humanos en los países mediante otras fuentes, entre ellas las organizaciones no gubernamentales, organismos de las Naciones Unidas, otras organizaciones intergubernamentales, instituciones académicas y la prensa. Teniendo presente toda la información disponible, el Comité examina el informe junto con los representantes oficiales del Estado Parte. Sobre la base de este diálogo, el Comité expresa sus preocupaciones y recomendaciones, conocidas como "Observaciones Finales", las cuales son públicas. El Comité también hace pública su interpretación del contenido de las disposiciones de los derechos recogidos en la Convención, que se conocen como "Observaciones Generales", así mismo expresa recomendaciones generales sobre cuestiones temáticas o sobre sus métodos de trabajo.

Si nos adentramos al tratado en sí, nos vamos a encontrar diferentes provisiones que tratan de tutelar el derecho a la educación para un sector específico: la niñez. Al respecto, habría que hacer la primera salvedad, en el sentido de que para los efectos de este instrumento se entiende por niñez a "...todo ser humano menor de dieciocho años de edad, salvo que en virtud de la ley que le sea aplicable, haya alcanzado antes la mayoría de edad" (art. 1). 
Por otra parte, empezamos acotando que el artículo 19 del Convenio dispone que los Estados Partes deben adoptar toda clase de medidas, sea de índole legislativa; administrativa; sociales y educativas apropiadas para "proteger al niño contra toda forma de perjuicio o abuso físico o mental, descuido o trato negligente, malos tratos o explotación, incluido el abuso sexual, mientras el niño se encuentre bajo la custodia de los padres, de un representante legal o de cualquier otra persona que lo tenga a su cargo". A su vez esta garantía se complementa con la prevista en el artículo 27 que enuncia lo siguiente:

1. Los Estados Partes reconocen el derecho de todo niño a un nivel de vida adecuado para su desarrollo físico, mental, espiritual, moral y social.

2. A los padres u otras personas encargadas del niño les incumbe la responsabilidad primordial de proporcionar, dentro de sus posibilidades y medios económicos, las condiciones de vida que sean necesarias para el desarrollo del niño.

Se hace vital destacar que los artículos 28 y 29 establecen claramente derroteros precisos por cumplir en materia del derecho a la educación para la niñez. En primera instancia tenemos que el artículo 28 se comporta como un catálogo de políticas a seguir por parte de los Estados suscriptores del convenio, y es así como se han fijado a manera de ilustración, las siguientes:

1. Los Estados Partes reconocen el derecho del niño a la educación y, a fin de que se pueda ejercer progresivamente y en condiciones de igualdad de oportunidades ese derecho, deberán en particular:

a) Implantar la enseñanza primaria obligatoria y gratuita para todos;

b) Fomentar el desarrollo, en sus distintas formas, de la enseñanza secundaria, incluida la enseñanza general y profesional, hacer que todos los niños dispongan de ella y tengan acceso a ella y adoptar medidas apropiadas tales como la implantación de la enseñanza gratuita y la concesión de asistencia financiera en caso de necesidad;

c) Hacer la enseñanza superior accesible a todos, sobre la base de la capacidad, por cuantos medios sean apropiados;

d) Hacer que todos los niños dispongan de información y orientación en cuestiones educacionales y profesionales y tengan acceso a ellas;

e) Adoptar medidas para fomentar la asistencia regular a las escuelas y reducir las tasas de deserción escolar. 
2. Los Estados Partes adoptarán cuantas medidas sean adecuadas para velar por que la disciplina escolar se administre de modo compatible con la dignidad humana del niño y de conformidad con la presente Convención.

3. Los Estados Partes fomentarán y alentarán la cooperación internacional en cuestiones de educación, en particular a fin de contribuir a eliminar la ignorancia y el analfabetismo en todo el mundo y de facilitar el acceso a los conocimientos técnicos y a los métodos modernos de enseñanza. A este respecto, se tendrán especialmente en cuenta las necesidades de los países en desarrollo".

Con respecto al párrafo primero del artículo $29^{5}$, el Comité de Derechos del Niño se ha servido realizar toda una interesante observación general, explicando la dimensión, contenido y operatividad del derecho a la educación en la población menor de dieciocho años (ONU-Comité derechos del niño: 2001). Comienza diciéndonos el Comité de Derechos del Niño, que "El párrafo 1 del artículo 29 de la Convención sobre los Derechos del Niño reviste una importancia trascendental. Los propósitos de la educación que en él se enuncian y que han sido acordados por todos los Estados Partes, promueven, apoyan y protegen el valor supremo de la Convención: la dignidad humana innata a todo niño y sus derechos iguales e inalienables" (párrafo primero).

Estos propósitos, enunciados en los cinco incisos del párrafo 1 del artículo 29 están directamente vinculados con el ejercicio de la dignidad humana y los derechos del niño y de la niña, habida cuenta de sus necesidades especiales de desarrollo y las diversas capacidades en evolución. Los objetivos son el desarrollo holístico del niño hasta el máximo de sus posibilidades (29 (1) (a)), lo que incluye inculcarle el respeto de los derechos humanos (29 (1) (b)), potenciar su sensación de identidad y pertenencia (29 (1) (c)) y su integración en la sociedad e interacción con otros (29 (1) (d)) y con el medio ambiente (29 (1) (e)).

Interesante resulta indagar, como lo hizo el Comité, en torno a la dimensión cualitativa del derecho a la educación que encierra este artículo, todo ello trata de conjugar que los procesos educativos giren sobre el mejor interés del niño(a), en términos que le ayuden y favorezcan en su desarrollo personal ${ }^{6}$. Asimismo, el artículo 29, nos dice que los Estados Partes convienen en que la educación del niño deberá estar encaminada a una "...amplia gama de valores. Este consenso atraviesa las líneas divisorias que han trazado las religiones, las naciones y las culturas en muchas partes del mundo" (párrafo cuarto). Lo anterior tiene estrecha relación con el crecimiento educativo del menor, asimilando que el 
desarrollo personal va aparejado con iniciativas para fomentar la comprensión, la tolerancia y la amistad entre todos los pueblos a que se refiere el inciso d) del párrafo 1 del citado artículo.

Un aspecto loable que se debe destacar es el concerniente a precisar que las prácticas discriminatorias en contra de la población educativa, no son de recibo en el marco de la Convención de Derechos del Niño. Al respecto el mismo Comité que nos ocupa, ha dicho que "(...) desea destacar los nexos entre el párrafo 1 del artículo 29 y la lucha contra el racismo, la discriminación racial, la xenofobia y las formas conexas de intolerancia. Los fenómenos del racismo y sus derivados medran donde imperan la ignorancia, los temores infundados a las diferencias raciales, étnicas, religiosas, culturales y lingüísticas o de otro tipo, la explotación de los prejuicios o la enseñanza o divulgación de valores distorsionados". Prosigue diciéndonos esta instancia que "Una educación que promueva el entendimiento y aprecio de los valores que se exponen en el párrafo 1 del artículo 29, entre ellos el respeto de las diferencias, y que ponga en tela de juicio todos los aspectos de la discriminación y los prejuicios constituirá un antídoto duradero y seguro contra todos estos extravíos" (párrafo 11).

Otro aspecto importante de mencionar es el del planteamiento bolístico de la educación, el cual garantice que las oportunidades educativas disponibles reflejen un equilibrio satisfactorio entre la promoción de los aspectos físicos, mentales, espirituales y emocionales entre la educación, las dimensiones intelectuales, sociales y prácticas, y los aspectos correspondientes a la infancia y al resto de la vida. Se hace hincapié en que el tipo de enseñanza que se concentra fundamentalmente en la acumulación de conocimientos, que estimula la competencia e impone a la niñez una carga excesiva de trabajo puede ser un grave impedimento para el desarrollo armonioso del niño y de la niña hasta realizar todo el potencial de sus capacidades y aptitudes. La educación debe ser favorable a la niñez y debe inspirar y motivar a cada uno de ellos. Las escuelas deben fomentar un clima humano y permitir a los niños que se desarrollen según la evolución de sus capacidades (párrafo 12).

En referencia a la interrogante de cómo debe ser el entorno escolar en aras de propiciar la implementación de estos principios, tenemos que el Comité la dimensiona en la práctica de educación en la esfera de derechos humanos, y esta simbiosis ha sido definida de la siguiente manera: 
...debe reflejar la libertad y el espíritu de entendimiento, paz, tolerancia, igualdad entre los sexos y amistad entre todos los pueblos, grupos étnicos, nacionales y religiosos y personas de origen indígena, por los que se aboga en los incisos b) y d) del párrafo 1 del artículo 29. Una escuela en la que se permita la intimidación de los más débiles u otras prácticas violentas o excluyentes no cumple con los requisitos del párrafo 1 del artículo 29. El término "educación en la esfera de los derechos humanos" se utiliza con demasiada frecuencia de una forma tal que sus connotaciones se simplifican en exceso. Además de una educación oficial en materia de derechos humanos, lo que hace falta es promover los valores y las políticas que favorecen los derechos humanos, no sólo en las escuelas y universidades, sino también en el seno de la comunidad entera. (párrafo 19)

El Comité exhorta a los Estados Partes a prestar más atención a la educación, considerándola como un proceso dinámico, y a idear los medios para valorar las modificaciones experimentadas con el correr del tiempo, en relación con el párrafo 1 del artículo 29. La buena calidad educativa va de la mano con estudios que puedan brindar una oportunidad para evaluar los progresos realizados, basados en el análisis de las ideas de todos los participantes en el proceso, inclusive de la niñez que asisten ahora a la escuela o que ya han terminado su escolaridad, de los maestros y los dirigentes juveniles, de los padres y de los supervisores y administradores en la esfera de la educación. A este respecto, el Comité destaca el papel de la supervisión a escala nacional que trata de garantizar que los niños, los padres y los maestros puedan participar en las decisiones relativas a la educación (párrafo 22). Es así como se propone a los Estados Partes elaborar un plan nacional integral de acción para promover y supervisar el logro de los objetivos que se enuncian en el párrafo 1 del artículo 29. Aunque este plan se elabore en el marco más amplio de un plan nacional para la infancia, un plan nacional de acción en materia de derechos humanos o una estrategia nacional de educación en la esfera de los derechos humanos, el gobierno debe velar por que se aborden todas las cuestiones de las que se ocupa el párrafo 1 del artículo 29 y siempre desde la perspectiva de los derechos del niño (párrafo 23).

Con el objetivo de tutelar las posibles violaciones a las garantías estipuladas en la norma genérica en estudio, el Comité también ha exhortado para que se establezca un procedimiento de examen que responda a las denuncias de que las actuales políticas o prácticas no son compatibles con el párrafo 1 del artículo 29. Estos procedimientos de 
examen no implican necesariamente la creación de nuevos órganos judiciales, administrativos o docentes, sino que también podrían confiarse a instituciones nacionales de derechos humanos o a los actuales órganos administrativos. Por último, para ejecutar los planes nacionales integrales de acción destinados a potenciar el cumplimiento de lo estipulado, se necesitan recursos humanos y financieros hasta el máximo de que se disponga, de conformidad con el artículo 4 del Convenio. Por consiguiente, el Comité considera que la limitación de recursos no justifica que un Estado Parte no adopte ninguna de las medidas necesarias, o las suficientes. Esta percepción va muy ligada a lo que el Comité de Derechos Económicos, Sociales y Culturales denominó como contenido mínimo $u$ obligación mínima, en su Observación General N 3 de 1990 y que consiste básicamente en establecer que todos los Estados Partes deben asegurar, al menos, la satisfacción de niveles esenciales mínimos de cada uno de los derechos consagrados en el Pacto Internacional de Derechos Económicos, Sociales y Culturales (Chacón, 2007, p. 26), siendo el derecho a la educación uno de los derechos consagrados.

\subsection{La Relatoría del Derecho a la Educación dentro del sistema universal de protección a los derechos humanos}

La antigua Comisión de Derechos Humanos de la Organización de las Naciones Unidas -hoy Consejo de Derechos Humanos- y el Consejo Económico y Social (ECOSOC), han establecido varios procedimientos y mecanismos extraconvencionales que se han confiado bien a grupos de trabajo compuestos por expertos que actúan a título personal o bien a particulares independientes denominados relatores especiales, representantes 0 expertos. Los mandatos conferidos a esos procedimientos y mecanismos consisten en examinar y vigilar, ya sea la situación de los derechos humanos en países o territorios específicos (los llamados mecanismos o mandatos por país) o fenómenos importantes de violaciones de los derechos humanos a nivel mundial (los mecanismos o mandatos temáticos), e informar públicamente al respecto en ambos casos.

Se hace oportuno precisar terminológicamente, qué debe entenderse por relator especial, por lo que debemos expresar inicialmente que este mecanismo extraconvencional ha sido definido como aquella persona nombrada por el Presidente de la Comisión de Derechos Humanos -hoy Consejo de Derechos Humanos-, previa consulta con los demás miembros de la mesa, con el mandato de realizar un estudio a fondo sobre la situación de los derechos humanos en un país determinado o sobre un aspecto temático bien determinado

Volumen 7, Número 2, Año 2007, ISSN 1409-4703 
(Segura en González Volio, 1996, p. 327). Este relator se constituye en un experto independiente, capaz de elaborar un Informe a fondo sobre la situación de los derechos humanos en el país determinado, a la vez que en dicho documento de análisis debe incluir los puntos de vista de los diferentes sectores sociales y políticos implicados ${ }^{7}$.

Esos expertos constituyen actualmente lo que se ha dado en llamar mecanismos o mandatos de derechos humanos de las Naciones Unidas o el sistema de procedimientos especiales. Pese a que cada titular de un mandato tiene un nombre diferente, como relator especial, representante especial o experto independiente, se considera que todos son «expertos en misión» en el sentido de la Convención sobre los Privilegios e Inmunidades de las Naciones Unidas de 1946. Para el caso específico del campo de la educación, tenemos que en su resolución 1998/33, la Comisión de Derechos Humanos estableció el mandato del Relator Especial sobre el derecho a la educación, correspondiendo a la Sra. Katarina Tomasevski (Croacia), constituirse desde 1998 en la primera relatora. En agosto del 2004, la Comisión, por su resolución 2004/25, prorrogó el mandato por un período de tres años, siendo esta vez el Sr. Vernor Muñoz Villalobos (Costa Rica), nombrado como nuevo Relator Especial. En esta encomiable labor, se han elaborado sendos y valiosos informes que denotan diferentes preocupaciones sobre el quehacer educativo mundial, abordando no solo tópicos generales, sino concretos sobre problemáticas inherentes a diferentes países ${ }^{8}$.

Sentimos que el concurso de las Relatorías Especiales, y sobre todo del Relator(a) del derecho a la educación, es sumamente importante, debido a que contribuye a presentar denuncias directas ante el Sistema de la Organización de las Naciones Unidas sobre diferentes tópicos generales y a su vez, correlativamente con los informes de situación específicos se pone en evidencia a los países infractores ante la comunidad internacional. A pesar que se ha dicho que el sistema de informes, no es un mecanismo apropiado para la exigibilidad inmediata de los derechos sociales -como lo es el derecho a la educación-, estimamos que la denuncia se torna necesaria y entroniza en los países que menoscaban este derecho, la necesidad de llegar a arreglos en torno a la situación evidenciada. Es esta la verdadera dimensión de la moral de los Estados, quienes no desean verse compelidos a incumplir normas de jus cogens o de práctica aceptada internacionalmente y en este sentido, la censura de la comunidad internacional juega un importante rol para exigir el cumplimiento de los mismos Estados infractores. 


\subsection{La labor de la UNESCO y la salvaguarda del derecho a la educación}

La Organización de las Naciones Unidas para la Educación, la Ciencia y la Cultura (UNESCO) es un organismo especializado del sistema universal de protección de los derechos humanos. La misión de la UNESCO es promover la educación como un derecho fundamental, mejorar la calidad de la educación y estimular le experimentación, la innovación y el diálogo en materia de política. El artículo primero de la UNESCO, redactado en Londres en noviembre de 1945, estipula que "La Organización se propone contribuir a la paz y a la seguridad estrechando mediante la educación, la ciencia y la cultura, la colaboración entre las naciones, a fin de asegurar el respeto universal a la justicia, a la ley, a los derechos humanos y a las libertades fundamentales..."

Una de las funciones de la UNESCO según lo establece su propio pacto constitutivo, radica en recomendar aquellos convenios o acuerdos internacionales que sean necesarios para la consecución de los propósitos de la Organización. De los veintisiete convenios protocolos y otros acuerdos adoptados, tanto en el marco de la conferencia general como por las conferencias intergubernamentales especializadas; la gran mayoría está relacionada con los derechos humanos y en especial, con los derechos a la educación, a la cultura y a la información, contemplados en los artículos 26, 27 y 19 de la Declaración Universal.

La UNESCO ha diseñado megaproyectos a escala global, tales como el "Plan de acción mundial", que es una estrategia global elaborada para mejorar la coordinación de la Educación para todos a nivel internacional y nacional. Tiene por objetivo clarificar el rol de cada una de las cinco agencias líderes del movimiento de la Educación Para Todos, gestado en la Conferencia Mundial celebrada en Tailandia (Banco Mundial, FNUAP, PNUD, UNESCO y UNICEF) y definir su acción conjunta y coordinada a nivel mundial. Por fin, tiene como objetivo orientar mejor la acción sobre el terreno a nivel nacional, para cumplir diferentes metas.

Asimismo, tenemos que el "Informe Mundial de Seguimiento" es una publicación anual que hace referencia y que evalúa los progresos de los países y agencias hacia la realización de los objetivos de la Educación Para Todos (EPT). Proporciona los más recientes datos disponibles bajo un análisis elaborado con suma profundidad. Incluye un índice del desarrollo de la EPT, cuya intención consiste en medir los avances de los países con respecto a los lineamientos generados por la EPT, y más particularmente la enseñanza primaria, la alfabetización de los adultos, la igualdad entre los sexos y la calidad. Esta iniciativa se constituye así en un sistema de justiciabilidad del derecho a la educación a través del 
sistema de indicadores, tal como hemos abordado esta temática en otra oportunidad a través de este mismo espacio divulgativo en otra oportunidad (Chacón, 2006).

\subsubsection{Convenios y recomendaciones al amparo de la UNESCO}

Es importante destacar que la UNESCO ha gestado como auspiciadora diferentes convenios en el ámbito de los países miembros. En primer lugar podemos hablar de los convenios de convalidación de estudios ${ }^{9}$.

Existen además las siguientes recomendaciones dentro del seno de la UNESCO, que estimamos relevantes y dignas de ser mencionadas. Aunque su carácter sea de un mero documento consensuado y opera siempre en el ámbito recomendativo o no vinculante, contiene provisiones que pueden ser adoptadas dentro de la legislación interna de los países miembros. Es así como tenemos la "Recomendación relativa a la condición del Personal Docente" (5/10/1966); "Recomendación sobre la Educación para la comprensión, la cooperación y la paz internacionales y la educación relativa a los derechos humanos y las libertades fundamentales" (19/11/1974); o la "Recomendación relativa al desarrollo de la Educación de Adultos" (26/11/1976). Más contemporáneamente tenemos la adopción de la "Recomendación revisada relativa a la Enseñanza Técnica y Profesional" (2/11/2001).

\subsubsection{Otras actividades desarrolladas por la UNESCO.}

Aunada a la práctica anterior de adopción de convenios y recomendaciones gestadas por la UNESCO, tenemos que esta instancia internacional ha incursionado en otras actividades. En diciembre de 2002, la Asamblea General de las Naciones Unidas adoptó la resolución 57/254 relativa al Decenio de las Naciones Unidas de la Educación para el Desarrollo Sostenible (2005-2014) y designó a la UNESCO como órgano responsable de la promoción del Decenio.

Como consecuencia de lo anteriormente expuesto, se intenta gestar una educación de calidad, la cual es condición previa a la educación para el desarrollo sostenible. La Educación para el Desarrollo Sostenible alcanza varios ámbitos, que reflejan diversos objetivos y audiencias, entre ellos:

- Promoción y mejora de la Educación Básica.

- Reorientación de los Programas de Educación a todo nivel, con dirección al desarrollo sostenible.

- Desarrollar Conciencia y Comprensión Pública sobre la Sostenibilidad. 
- Impartir formación.

- Involucrar a la Educación Superior.

Se caracteriza igualmente a esta educación sostenible como la capacidad evolutiva de hacer realidad una abstracción. Esta facultad que implica desarrollar las capacidades individuales y sociales para trabajar por un futuro sostenible es, esencialmente, una empresa educativa. De hecho, los cuatro principios para alcanzar el desarrollo humano formulado en la Cumbre Mundial sobre el Desarrollo Sostenible en 2002, requiere entre otras cosas las siguientes: i) Reconocimiento del cambio; ii) Responsabilidad colectiva y asociación constructiva; iii) Actuar con determinación y iv) La entereza de la dignidad humana.

Así, la educación es el principal agente de la transición hacia el desarrollo sostenible, que incrementa la capacidad de las personas de hacer realidad sus concepciones de la sociedad. La educación no se limita a impartir capacidades científicas y técnicas, también refuerza la motivación, la justificación y el apoyo social a las personas que los buscan y los aplican. La comunidad internacional está convencida de que necesitamos desarrollar -por medio de la educación - los valores, el comportamiento y el estilo de vida indispensables para un futuro sostenible. La educación para el desarrollo sostenible se percibe como un proceso de aprendizaje para tomar decisiones que tengan en cuenta a largo plazo el futuro de la economía, la ecología y la equidad de todas las comunidades. Pretender crear la capacidad de prever el futuro constituye la principal misión de la educación, y claro está, la sostenibilidad del entorno se constituye en un objetivo no solo estratégico, sino además netamente existencial.

\section{La Educación en Conferencias Mundiales y otras iniciativas multilaterales}

A lo largo de este capítulo pretendemos esbozar a manera de recuento la manera en que se ha abordado el fenómeno de la educación en las diferentes conferencias mundiales contemporáneas convocadas por la comunidad internacional. Unas han asumido esta temática como objetivo único de la conferencias, otras han abordado la problemática educativa de una manera colateral y esencial, logrando que se alcance una incidencia en el fenómeno por analizar, según lo vamos a resaltar. De igual manera, haremos mención a la Declaración del Milenio adoptada por la Organización de las Naciones Unidas. 


\subsection{Conferencia Mundial sobre Educación para Todos (1990)}

Del 5 al 9 de marzo de1990 se celebra en Jomtien, Tailandia, la Conferencia Mundial que adopta la Declaración de Educación para todos: Satisfacción de las necesidades básicas de aprendizaje. La justificación de esta iniciativa residía en datos estadísticos sumamente contundentes: más de 100 millones de niños y de niñas, de los cuales 60 por lo menos son niñas, no tienen acceso a la enseñanza primaria; más de la tercera parte de los adultos del mundo carecen de acceso al conocimiento impreso y a las nuevas capacidades y tecnologías que podrían mejorar la calidad de su vida y ayudarles a dar forma y adaptarse a los cambios sociales y culturales, y finalmente, en el orden de 100 millones de niños e innumerables adultos no consiguen completar el ciclo de educación básica; y hay millones que, aun completándolo, no logran adquirir conocimientos y capacidades esenciales.

El texto comprende diez artículos, entre los que podemos destacar el de "Satisfacción de las necesidades básicas de aprendizaje" (art.1), que impone el imperativo de que cada persona -niño, niña, joven o adulto- deberá estar en condiciones de aprovechar las oportunidades educativas ofrecidas para satisfacer sus necesidades básicas de aprendizaje. Estas necesidades abarcan tanto las herramientas esenciales para el aprendizaje (como la lectura y la escritura, la expresión oral, el cálculo, la solución de problemas), como los contenidos básicos del aprendizaje (conocimientos teóricos y prácticos, valores y actitudes) necesarios para que los seres humanos puedan sobrevivir, desarrollar plenamente sus capacidades, vivir y trabajar con dignidad, participar plenamente en el desarrollo, mejorar la calidad de su vida, tomar decisiones fundamentadas y continuar aprendiendo. Por su parte, el artículo segundo denominado "Educación para Todos: Una visión ampliada y un compromiso renovado", nos dice que para satisfacer las necesidades básicas de aprendizaje exige algo más que una renovación del compromiso con la educación básica en su estado actual. Lo que se requiere es una "visión ampliada" que vaya más allá de los recursos actuales, las estructuras institucionales, los planes de estudios y los sistemas tradicionales de instrucción, tomando como base lo mejor de las prácticas en uso.

Esa visión ampliada, tal como se expone en los Artículos 3 al 7 de esta Declaración, comprende lo siguiente:

- Universalizar el acceso a la educación y fomentar la equidad.

- Prestar atención prioritaria al aprendizaje.

- Ampliar los medios y el alcance de la educación básica.

- Mejorar el ambiente para el aprendizaje. 
- Fortalecer concertación de acciones.

- Convertir en realidad el enorme potencial existente para el progreso y el incremento de las posibilidades de los individuos, depende de que se posibilite a estos para adquirir la educación y el impulso necesarios a fin de utilizar la masa de conocimientos útiles en constante expansión y aprovechar los nuevos medios de transmisión de esos conocimientos.

El artículo décimo habla de "Fortalecer la solidaridad internacional", entendida esta misión como La comunidad mundial, incluidos los organismos e instituciones intergubernamentales, tienen la responsabilidad urgente de atenuar las limitaciones que impiden a algunas naciones alcanzar la meta de la educación para todos. Ello requerirá adoptar medidas que incrementen los presupuestos nacionales de los países más pobres o ayuden a aliviar la carga de la pesada deuda que padecen. Acreedores y deudores deben tratar de encontrar fórmulas nuevas y equitativas para reducir esa carga, ya que la capacidad de muchos países en desarrollo para hacer frente eficazmente a las necesidades de educación y a otras necesidades básicas se reforzaría considerablemente si se encontrasen soluciones al problema de la deuda.

Años después, la Conferencia Mundial del Cairo sobre Población, estableció como una de las medidas por adoptar:

11.6 La erradicación del analfabetismo es condición indispensable para el desarrollo humano. Todos los países deberían consolidar los progresos efectuados en el decenio de 1990 con miras a facilitar el acceso universal a la enseñanza primaria, como se convino en la Conferencia Mundial sobre Educación para Todos, celebrada en Jomtien (Tailandia) en 1990, particularmente garantizando el acceso universal a la enseñanza primaria. Todos los países deberían procurar asegurar el acceso de todas las niñas y niños a la escuela primaria o a un nivel equivalente de enseñanza a la mayor brevedad posible, y en cualquier caso antes del año 2015.

El movimiento de la Educación para todos es un compromiso mundial para proveer una educación básica de calidad a todos los niños, niñas, jóvenes y adultos. El movimiento se inició durante la Conferencia mundial de 1990 y diez años después, como numerosos países no alcanzaron el objetivo fijado, la comunidad internacional se reunió de nuevo en Dakar, Senegal (2000), y reiteró su compromiso de realizar la Educación para todos de aquí al año 
2015. Se identificaron seis objetivos educativos a fin de responder a las necesidades de aprendizaje de todos los niños, niñas, jóvenes y adultos de aquí al año 2015.

Dos de los principales mecanismos de coordinación de la EPT son el Grupo de alto nivel y el Grupo de trabajo. El primer grupo es convocado anualmente por el Director general de la UNESCO, reúne unos treinta ministros de la Educación y de la Cooperación internacional, jefes de agencias para el desarrollo y representantes de la sociedad civil y del sector privado. Su papel es contribuir a reforzar la voluntad política iniciada durante el Foro Mundial sobre la Educación y movilizar recursos con la finalidad de ejecutar diferentes iniciativas. Por su parte, el Grupo de trabajo sobre la Educación para todos, proporciona una orientación técnica y promueve el intercambio de informaciones entre todos los asociados del movimiento de la Educación para todos.

Todos los años se realiza la Semana Mundial de Acción a favor de la Educación para Todos y consiste en una campaña mundial de sensibilización organizada por la Campaña Mundial para la Educación con el apoyo de la UNESCO. Se realiza a fines de abril en conmemoración del Foro Mundial sobre la Educación para Todos que tuvo lugar en 2000 en Dakar. Su objetivo es movilizar a los gobiernos y a la comunidad internacional para que tengan su compromiso de una Educación para Todos de aquí al año 2015.

\subsection{Conferencia Mundial de Derechos Humanos (1993)}

Empezaremos diciendo que durante la Conferencia Mundial de Derechos Humanos, celebrada en Viena, Austria en el año 1993, se puso énfasis en torno a que la educación en derechos humanos es de vital preponderancia. Al respecto en Viena se destacó que "la educación, la capacitación y la información pública de derechos humanos son elementos esenciales para fomentar y concretar relaciones estables y armónicas entre las comunidades y para promover la comprensión mutua, tolerancia y paz". Sin duda alguna, esta Conferencia Mundial, la segunda en la historia -después de la de Teherán en 1968-, incorpora importantes nociones del previamente elaborado concepto de derecho al desarrollo ${ }^{10}$.

En palabras del jurista brasileño, ex Juez de la Corte Interamericana de Derechos Humanos, Dr. Antonio Cancado Trindade; la relación entre la Conferencia Mundial y el derecho al desarrollo, se manifiesta en la forma siguiente:

La Declaración reclama un mayor fortalecimiento en la interrelación entre la democracia, el desarrollo y los derechos humanos en todo el mundo, abogando la protección universal de estos últimos sin imposición de condicionalidades. Un grato momento de los trabajos del Comité de Redacción fue el de la aprobación de la 
sección relativa al derecho al desarrollo como un derecho humano universal e inalienable, como estaba anteriormente proclamado en la Declaración de las Naciones Unidas de 1986 sobre el Derecho al desarrollo. La referida sección, además de endosar la Declaración antes citada de 1986, clama a la realización del derecho al desarrollo de manera de atender equitativamente "las necesidades ambientales y de desarrollo de las generaciones presentes y futuras" (párrafos 10-11), e insta a la comunidad internacional a que desarrolle esfuerzos para aliviar el peso de la deuda externa de los países en desarrollo, de modo a contribuir a la realización plena de los derechos económicos, sociales y culturales de su población. (Cancado, 1995, pp. 2627)

Para Villán Durán, la Declaración de Viena reafirmó el derecho al desarrollo como "derecho universal e inalienable y como parte integrante de los derechos humanos fundamentales", siendo la persona humana el sujeto central del desarrollo. Por lo mismo, la Declaración fue elocuente al subrayar que el desarrollo propicia el disfrute de todos los derechos humanos, pero la falta de desarrollo no puede invocarse como justificación para limitar los derechos humanos internacionalmente reconocidos (Villán Durán, 1998, p. 203).

Sobre los postulados propios de esta Declaración, tenemos que el punto décimo enuncia que "El desarrollo propicia el disfrute de todos los derechos humanos..." y señala que para hacer realidad este derecho se requiere de políticas domésticas efectivas, en conjunción con relaciones económicas justas en el orden internacional. Asimismo, el punto onceavo señala que "El derecho al desarrollo debe realizarse de manera que satisfaga equitativamente las necesidades en materia de desarrollo y medio ambiente de las generaciones actuales y futuras". Nos hemos referido a la noción de desarrollo, puesto que la misma deviene en una terminología integradora, en la que la educación es de vital preponderancia, según la "Declaración del Derecho al Desarrollo", adoptada por la Asamblea General en su resolución 41/128, de 4 de diciembre de 1986. Al respecto, este derecho al desarrollo podríamos denominarlo como un derecho síntesis, puesto que como lo expone el artículo primero de la citada declaración, “....es un derecho humano inalienable en virtud del cual todo ser humano y todos los pueblos están facultados para participar en un desarrollo económico, social, cultural y político en el que puedan realizarse plenamente todos los derechos humanos y libertades fundamentales, a contribuir a ese desarrollo y a disfrutar del él". Por último, el párrafo primero del artículo octavo manifiesta que la concreción del denominado derecho al desarrollo debe plasmarse en lo siguiente: 
1. Los Estados deben adoptar, en el plano nacional, todas las medidas necesarias para la realización del derecho al desarrollo y garantizarán, entre otras cosas, la igualdad de oportunidades para todos en cuanto al acceso a los recursos básicos, la educación, los servicios de salud, los alimentos, la vivienda, el empleo y la justa distribución de los ingresos. Deben adoptarse medidas eficaces para lograr que la mujer participe activamente en el proceso de desarrollo. Deben hacerse reformas económicas y sociales adecuadas con objeto de erradicar todas las injusticias sociales.

La importancia de que se tome en cuenta el derecho a la educación, ligado al derecho al desarrollo, no solo dentro de la Declaración de Viena de 1993 sino que dentro de la Declaración específica de 1986, radica en que no es posible hablar del primer derecho, si el mismo no va aparejado de una serie de condiciones institucionales y sobre todo materiales, que le den soporte. El desarrollo no es un factor o actividad neutra y conlleva adoptar una serie de mecanismos proactivos entre los que la educación desempeña un rol determinante.

\subsection{Conferencia Mundial de Población (1994)}

A su vez, la Conferencia Mundial de Población, celebrada en El Cairo, capital egipcia, del 5 al 13 de diciembre de 1994, en el capítulo XI del informe final de la conferencia denominado como POBLACIÓN, DESARROLLO Y EDUCACION, se refiere al fenómeno de la educación en el punto 11.1, de la siguiente manera:

En los últimos 20 años se ha registrado un aumento del nivel de educación en todo el mundo. A pesar de que se han reducido las diferencias en el grado de instrucción de los hombres y las mujeres, el $75 \%$ de los analfabetos del mundo son mujeres. La falta de enseñanza básica y los bajos niveles de alfabetización de los adultos continúan limitando el proceso de desarrollo en todos los ámbitos. La comunidad mundial tiene la responsabilidad especial de garantizar que todos los niños reciban una enseñanza mejor y que terminen el ciclo primario. La enseñanza es un instrumento indispensable para mejorar la calidad de la vida. Sin embargo, cuando hay un rápido crecimiento demográfico es más difícil atender a las necesidades educacionales.

La enseñanza es visualizada como un factor para aumentar el bienestar a causa de sus vínculos con los factores demográficos y los factores económicos y sociales. Los avances en este campo contribuyen en gran medida a la reducción de las tasas de fecundidad, morbilidad y mortalidad, a la habilitación de las mujeres, al mejoramiento de la calidad de la fuerza de trabajo y al fomento de una auténtica democracia política. La 
integración de los migrantes también se ve facilitada por el acceso universal a la enseñanza, respetando las creencias religiosas y la cultura de los migrantes (punto 11.2).

Además, el documento nos enuncia que existe una relación de interdependencia entre la educación y los cambios demográficos y sociales. Al respecto, dice lo siguiente:

Hay una estrecha y compleja relación entre la educación, la edad al casarse, la fecundidad, la mortalidad, la movilidad y la actividad. El aumento del nivel de educación de las mujeres y las niñas contribuye a una mayor habilitación de las mujeres, a un retraso de la edad en que se casan y a la reducción del tamaño de las familias. Cuando las madres están mejor educadas, la tasa de supervivencia de sus hijos tiende a aumentar. Un mayor acceso a la educación también es un factor de la migración interna y de la composición de la fuerza de trabajo. (11.3)

Finalmente los objetivos fijados en este capítulo serían los siguientes: a) Lograr el acceso de todos a una enseñanza de calidad, dando especial prioridad a la enseñanza primaria y técnica y la capacitación para el empleo, la lucha contra el analfabetismo y la eliminación de las desigualdades entre los sexos con respecto al acceso, la retención y el apoyo a la educación; b) Promover la educación no académica para los jóvenes, garantizando la igualdad de acceso de hombres y mujeres a los centros de alfabetización; c) Incorporar en los programas de estudios temas sobre la relación entre la población y el desarrollo sostenible, las cuestiones de salud, incluida la salud reproductiva, y la igualdad entre los sexos, y mejorar su contenido a fin de fomentar una mayor responsabilidad y conciencia al respecto.

Se establece finalmente el derecho a la educación bajo los términos siguientes en la citada conferencia:

Toda persona tiene derecho a la educación, que se deberá orientar hacia el pleno desarrollo de los recursos humanos; de la dignidad humana y del potencial humano, prestando especial atención a las mujeres y a las niñas. La educación se debería concebir de tal manera que fortaleciera el respeto de los derechos humanos y las libertades fundamentales, incluidos los relacionados con la población y el desarrollo. (UNESCO, 1996, p. 118)

\subsection{Cumbre de Desarrollo Social (1995)}

En la Cumbre Mundial sobre Desarrollo Social, celebrada del 6 al 12 de marzo de 1995 en Copenhague, Dinamarca, se hizo un balance alarmante de la situación social actual, 
recordando en particular que "más de mil millones de seres humanos en el mundo viven una pobreza abyecta y la mayoría padece hambre todos los días" y que "más de 120 millones de personas en el mundo están oficialmente desempleadas y muchas más están subempleadas". Este evento enfatizó en la educación y el desarrollo social, abordando la pobreza, el desempleo y la exclusión social, puso el acento en la contribución de las políticas educativas a su solución.

Hay que recordar las orientaciones que en esa Cumbre se formularon, pues aclaran adecuadamente la dimensión social de las políticas educativas. Los Estados participantes en ella se comprometieron a promover el acceso universal y equitativo a una enseñanza de calidad y a asegurar a todas las personas el nivel más elevado posible de salud física y mental y la atención primaria de salud. Declararon que, al respecto, se esforzarían especialmente por corregir las desigualdades de la condición social, sin distinción alguna por motivos de raza, origen nacional, sexo, edad o discapacidad física. Asimismo, se comprometieron a respetar y promover sus culturas comunes y particulares y a reforzar el papel que la cultura desempeña en el proceso de desarrollo y preservar los fundamentos esenciales de un progreso duradero centrado en el ser humano y a contribuir a la utilización óptima de los recursos humanos y al desarrollo social, con el fin de eliminar la pobreza, promover el pleno empleo y el empleo productivo y favorecer la integración social ${ }^{11}$.

\subsection{Conferencia Mundial de la Mujer (1995)}

Por su parte, en la Conferencia Mundial de la Mujer realizada en Beijing, China, en el mes de setiembre de 1995, se reafirma que

la educación constituye un derecho humano y una herramienta esencial para lograr los objetivos de igualdad, desarrollo y paz. La educación libre de actitudes discriminatorias beneficia tanto a niños como a niñas y eventualmente contribuye a igualar las condiciones entre hombres y mujeres.

El Anexo II del Informe de la Cuarta Conferencia Mundial sobre la Mujer es prolijo en acciones programáticas propicias para ser implementadas en el marco de la Plataforma de Beijing, China. Al respecto se establece un capítulo denominado "Educación y capacitación de la mujer" que contiene interesantes alcances y provisiones que deben ser respetadas principalmente por los Estados, en beneficio del derecho a la educación de las mujeres en 
general. A título de recuento, el párrafo 69 nos enuncia el espíritu que ha de acompañar al derecho a la educación con perspectiva de género:

La educación es un derecho humano y constituye un instrumento indispensable para lograr los objetivos de la igualdad, el desarrollo y la paz. La educación no discriminatoria beneficia tanto a las niñas como a los niños y, de esa manera, conduce en última instancia a relaciones más igualitarias entre mujeres y hombres. La igualdad de acceso a la educación y la obtención de educación son necesarias para que más mujeres se conviertan en agentes de cambio. La alfabetización de la mujer es importante para mejorar la salud, la nutrición y la educación en la familia, así como para habilitar a la mujer para participar en la adopción de decisiones en la sociedad. Ha quedado demostrado que la inversión en la educación y la capacitación formal y no formal de las niñas y las mujeres, que tiene un rendimiento social y económico excepcionalmente alto, es uno de los mejores medios de lograr un desarrollo sostenible y un crecimiento económico a la vez sostenido y sostenible. (ONU, 1995)

Se denuncia que en el plano mundial existen regiones en las que no se ha podido tener un acceso a la educación con igualdad para los niños y niñas -y se habla del caso de África con sesenta millones de niñas que no han alcanzado ese imperativo-, por lo que se hace perentorio generar la creación de un entorno educacional y social en el que se trate igualitariamente a las mujeres y los hombres, a las niñas y los niños, en el que se les aliente a alcanzar su pleno potencial, respetando su libertad de pensamiento, conciencia, religión y creencias (párrafo 72).

En aras de revertir situaciones como las anteriormente expuestas, la misma Conferencia Mundial adoptó en este Anexo II, una serie de objetivos estratégicos tales como el de "Asegurar la igualdad de acceso a la educación", con medidas que han de adoptarse como las siguientes: i) asegurar el acceso universal a la enseñanza básica y lograr que terminen la enseñanza primaria por lo menos el $80 \%$ de los niños para el año 2000; superar las diferencias por motivos de género que existan en el acceso a la enseñanza primaria y secundaria para el año 2005; y proporcionar enseñanza primaria universal en todos los países antes del año 2015; ii) establecer un sistema docente en que se tengan en cuenta las cuestiones relacionadas con el género, a fin de promover la igualdad de oportunidades de educación; iii) aumentar la matrícula y las tasas de retención escolar de las niñas, asignando a esa actividad los recursos presupuestarios necesarios; iv) promover un entorno docente en 
que se eliminen todas las barreras que impiden la asistencia a la escuela de las adolescentes embarazadas y las madres jóvenes.

Otro objetivo estratégico es el de "Eliminar el analfabetismo entre las mujeres" y que encierra medidas tales como las de i) reducir la tasa de analfabetismo femenino por lo menos a la mitad de la tasa de 1990, con especial hincapié en la alfabetización de las mujeres rurales, migrantes, refugiadas y desplazadas internamente, así como en las mujeres con discapacidades; ii) eliminar las diferencias por motivos de género en las tasas de alfabetización elemental y funcional de mujeres y hombres, como recomienda la Declaración de Jomtien sobre Educación para Todos. El tercer objetivo se denomina "Aumentar el acceso de las mujeres a la formación profesional, la ciencia y la tecnología y la educación permanente" con diferentes medidas que están encaminadas a la consecución de políticas inclusivas en esta esfera.

El cuarto objetivo ha sido clasificado como el de "Establecer sistemas de educación y capacitación no discriminatorios”, y entre las medidas por adoptar tenemos que los gobiernos, las autoridades educativas y otras instituciones educativas y académicas deben formular recomendaciones y elaborar planes de estudio, libros de texto y material didáctico libres de estereotipos basados en el género para todos los niveles de enseñanza, a la vez que no deben sentarse discriminaciones para las estudiantes de extracción rural; indígenas; y sobre todo debe promoverse la multiculturalidad en los diferentes textos y enfoques curriculares de las materias por impartir. Por último, se habla del quinto objetivo estratégico consistente en "Asignar recursos suficientes para las reformas de la educación y vigilar la aplicación de esas reformas" con medidas a adoptar tales como la de proporcionar al sector educativo los recursos financieros necesarios mediante la reasignación dentro de ese sector, a fin de garantizar un aumento de recursos para la enseñanza básica, según proceda, poniendo especial énfasis en la educación para las mujeres.

\subsection{Declaración del Milenio de la Organización de las Naciones Unidas}

En la octava sesión plenaria realizada el 8 de setiembre del 2000 por parte de la Asamblea General de la Organización de las Naciones Unidas, se adopta la Resolución 55/2 denominada "Declaración del Milenio". Esta declaración reviste la importancia de constituirse en un lineamiento de objetivos políticos por conseguir, y en este marco el capítulo III - 
denominado "El desarrollo y la erradicación de la pobreza"-, establece en el punto número 19 lo siguiente:

- Reducir a la mitad, para el año 2015, el porcentaje de habitantes del planeta cuyos ingresos sean inferiores a un dólar por día y el de las personas que padezcan hambre; igualmente, para esa misma fecha, reducir a la mitad el porcentaje de personas que carezcan de acceso a agua potable o que no puedan costearlo.

- Velar por que, para ese mismo año, los niños y niñas de todo el mundo puedan terminar un ciclo completo de enseñanza primaria y por que tanto las niñas como los niños tengan igual acceso a todos los niveles de la enseñanza.

Se habla entonces de la accesibilidad y universalidad, por lo menos de la educación básica o elemental, tomando en cuenta que es necesario completar un nivel básico de instrucción, cual es el terminar el ciclo primario. Sin embargo, debemos sacar como reflexión en este punto, que la meta educativa es mucho menos desafiante que lo externado por el Comité de DESC interpretando el artículo 13 del PIDESC, según lo analizamos en el punto 1.3 de este trabajo.

En esta Declaración del Milenio se pretende llegar aunque sea a un mínimo deseable para homologar hacia abajo, y no es visualizada la posibilidad de trascender más allá de la conclusión de la educación primaria. Sin duda alguna se habla de escolaridad básica entendida como alfabetización y la posibilidad de completar una instrucción elemental o básica.

\section{Consideraciones finales}

Hemos querido resaltar, con estas breves exposiciones de las principales disposiciones adoptadas en sendos instrumentos y conferencias mundiales, la importancia que conlleva el derecho a la educación. Creemos que la importancia del anterior recuento estriba en la necesidad de dejar patentizado, que la lucha por la observancia del derecho a la educación es una tarea constante en el ámbito internacional. Aunque existen abundantes provisiones normativas que imponen obligaciones positivas a los Estados suscriptores, lo cierto del caso es que se impone la necesidad de que los gobiernos actúen con mucha mayor coherencia y decisión política, puesto que existe un derrotero marcado; se requiere tomar decisiones concretas para tutelar derechos que de igual manera, son circunscritos al deber de contar con una adecuada educación para los hombres y mujeres de un determinado país. 
Hemos visto a lo largo de estas líneas, que si bien es cierto que existen preocupaciones coincidentes en el marco de la normativa internacional que regula el derecho a la educación -tales como la accesibilidad o cobertura; la no discriminación; obligatoriedad de brindar este servicio por parte del Estado-, los mecanismos de exigibilidad son muy diversos y tienden a la dispersión. A manera de ejemplo, existen los de índole convencional tales como los existentes en la Convención de Derechos del Niño y el Pacto Internacional de Derechos Económicos, Sociales y Culturales, que consisten en el sistema de informes rendidos ante Comités de Expertos. En el mismo ámbito de los mecanismos convencionales, tenemos que la "Convención relativa a la Lucha contra las Discriminaciones en la Esfera de la Enseñanza" tiene su propio protocolo encaminado a resolver las diferencias e inobservancias surgidas en la aplicación de este instrumento, a través de una comisión conciliadora

De igual manera se encuentran los de naturaleza extraconvencional que han sido diseñados no sobre la base de un tratado internacional en específico, sino que a través de una preocupación propia de la Organización de las Naciones Unidas. Tenemos así las figuras de las Relatorías Especiales, y como en el caso del derecho a la educación, existe un relator o mandatario que se encarga de diagnosticar y sugerir cambios cualitativos a la comunidad internacional, sobre este aspecto.

Otro mecanismo si se quiere más de corte político, lo constituyen las Conferencias Mundiales, las cuales según hemos visto presuponen un marcado y recurrente acento en el derecho a la educación. Así las cosas, y para citar tan solo un ejemplo demostrativo, si se valoran los derechos de las mujeres en el orden mundial, se enfoca la educación de este importante conglomerado humano. De igual manera se ha realizado este análisis en las otras cumbres mundiales (población; derechos humanos; social), y así lo hemos consignado. Sin embargo, no cabe la menor duda que si estas inquietudes no van acompañadas de una verdadera voluntad política; caemos en el absurdo de diseñar foros decorativos en los que abunda la retórica incapaz de traducirse en acciones mancomunadas y vinculantes concretas para los países participantes.

Haciendo una traslación al caso costarricense, tenemos que nuestro sistema jurídico privilegia una vigencia de los instrumentos de derechos humanos, encima de las propias normas constitucionales si estas últimas tienden a reducir la protección y vigencia del derecho regulado en el pacto internacional, según lo hemos expuesto al inicio de este trabajo. Lo anterior implica que si los estándares y disposiciones internacionales invocadas tienden a privilegiar, potenciar y realzarlo, entonces deben acatarse y son de absoluta jerarquía. 
El diagnóstico mundial del estado de la educación suele ser recurrente en muchos lugares: exclusión; analfabetismo; limitaciones presupuestarias; discriminación; etc. Por lo tanto, las necesidades por cumplimentar presentan los mismos diagnósticos en mayor medida, siendo que para el caso costarricense nos encontramos situaciones como que solamente un $40 \%$ de los jóvenes en edad de estudiar secundaria, lo están haciendo; las dos terceras partes no están estudiando formalmente (MIDEPLAN, 2007, p. 26). Nos preguntamos si faltará ejercer acción política más efectiva o hasta interponer quejas ante la jurisdicción interna tomando como parámetro lo dispuesto por el entorno internacional; como una medida de hacer efectivo el disfrute y goce del derecho a la educación. Con los instrumentos internacionales invocados, así como las interpretaciones que de éstos han generado los diferentes comités de expertos -en los casos de los convenios que establezcan dichos comités-, tenemos que existe un asidero propicio para hurgar en estos antecedentes y exigir al ordenamiento jurídico costarricense, que se cumplan las disposiciones insertas en estos tratados si a nivel local la protección se torna más débil. A manera de ejemplo igualmente, si deseamos escudriñar en relación a que se entiende por "derecho a la enseñanza técnica y profesional" en el contexto del PIDESC, recurrimos a la Observación General no 13 del Comité de derechos económicos, sociales y culturales, la cual ha establecido lineamientos que si son mejores y dan mayor protección de esta prerrogativa que lo estipulado en el ámbito interno; deben prevalecer y exigirse en nuestro ordenamiento jurídico inmediatamente.

Podemos traer a colación tantas otras situaciones en las que se pueden invocar las prerrogativas internacionales en detrimento de la legislación nacional, como por ejemplo la interpretación que ha realizado el Comité de Derechos del Niño en referencia al artículo 29 de la Convención de Derechos del Niño y su enfoque vasto y diverso sobre lo que significa "desarrollo holístico del niño". Si sentimos que las disposiciones administrativas y normativas en general prevalecientes en nuestro medio son más lesivas y restrictivas del derecho a la educación en la niñez que las dispuestas en el fuero endógeno, tendríamos asidero jurídico suficiente para exigir su tutela ante instancias de protección de los derechos humanos internacionales, como sería la propia Sala Constitucional de la Corte Suprema de Justicia

Precisamente en esta acción contrastativa radica la importancia de elaborar análisis de fondo normativo sobre el derecho a la educación, que de ser más restrictivos en el nivel endógeno, pueden complementarse en la dimensión internacional para exigir mayor tutela y garantías. Estimamos que existe base jurídica, o si se quiere fundamentos lo suficientemente sólidos que estipulan posibilidades y derecho a acceder a la educación, de manera inmediata. De lo contrario, nos vamos a encontrar que derecho que no se 
defiende....se pierde, y en esta labor de defensa y promoción, el entorno internacional tiene suficientes insumos que aportar.

\section{REFERENCIAS}

Cancado Trindade, Antonio. (1995). Balance de los Resultados de la Conferencia Mundial de Derechos Humanos (Viena 1993). En Estudios Básicos de Derechos Humanos, Vol III. San José: Instituto Interamericano de Derechos Humanos.

Chacón Mata, Alfonso. (2006, 30 de agosto). El uso de indicadores para justificar y exigir el derecho a la educación: Apuntes para un debate. Revista electrónica Actualidades Investigativas en Educación, 6 (2), artículo indicadores. Recuperado el 22 de julio de 2007 de http://revista.inie.ucr.ac.cr/articulos/2-2006/archivos/indicadores.pdf

Chacón Mata, Alfonso. (2007, marzo). Derechos económicos, sociales y culturales: indicadores y justiciabilidad. Cuadernos de Derechos Humanos. Bilbao, España: Universidad de Deusto.

Costa Rica, Ministerio de Planificación Económica y Social (MIDEPLAN). (2007). Plan Nacional de Desarrollo 2006-2010. San José: Imprenta Nacional, Mideplan.

Farrier Brais, Pedro, Lobo Quirós, Víctor Manuel y Peñaranda Segreda, Guido Arturo. (1988). Los Derechos Económicos, Sociales y Culturales en el Protocolo Adicional a la Convención Americana de Derechos Humanos (Pacto de San José). Seminario de Graduación para optar al título de licenciados en Derecho, Facultad de Derecho de la Universidad de Costa Rica, San José, Costa Rica.

García Méndez, Emilio. (1995). Infancia y Derechos Humanos. En Estudios Básicos de Derechos Humanos, Vol II. San José: Instituto Interamericano de Derechos Humanos.

González Volio, Lorena. (1996). Presente y futuro de los derechos humanos: Ensayos en honor a Fernando Volio Jiménez. San José: Instituto Interamericano de Derechos Humanos.

Organización de las Naciones Unidas (ONU). (1995, octubre). Informe de la Cuarta Conferencia Mundial sobre la Mujer (versión en español). Beijing: Autor.

Organización de las Naciones Unidas para la Educación, la Ciencia y la Cultura (UNESCO). (1996). La educación encierra un tesoro (informe de la Comisión Internacional sobre la Educación para el siglo XXI). Francia: Autor.

Organización de las Naciones Unidas. (2001). Instrumentos Internacionales de Derechos Humanos (versión en español). Nueva York: Autor.

Organización de las Naciones Unidas, Comité de Derechos del Niño. (2001). Observación General No 1: Propósitos de la educación-párrafo 1 del artículo 29 (versión en español). Ginebra, Suiza: Autor. 
Odio Benito, Elizabeth. (1990). La discriminación en el goce de los derechos humanos. En Instituto Interamericano de Derechos Humanos, Curso Interdisciplinario en Derechos Humanos: Manual de Conferencias. San José, Instituto Interamericano de Derechos Humanos.

UNESCO. (1996). La educación encierra un tesoro: Informe a la UNESCO de la Comisión Internacional sobre la educación para el siglo XXI (presidida por Jacques Delors). Madrid: Santillana.

Villán Durán, Carlos. (1998). La Declaración Universal de Viena y el derecho al desarrollo. En Revista Instituto Interamericano de Derechos Humanos No 6, San José, Instituto Interamericano de Derechos Humanos.

${ }^{2}$. Los principios básicos de la educación para la paz y los derechos humanos se han ido estableciendo en determinados instrumentos normativos de los cuales cabe citar; la Recomendación sobre la Educación para la Comprensión, la Cooperación y la Paz Internacionales y la Educación Relativa a los Derechos Humanos y las Libertades Fundamentales (París, 1974); el Plan de Acción para el Decenio de las Naciones Unidas para la Educación en la Esfera de los Derechos Humanos, 1995-2004 (París, 1995). Costa Rica y Uruguay pertenecen al Comité Consultivo para la Educación para la Paz, los Derechos Humanos, la Democracia y la Comprensión Internacional y la Tolerancia. UNESCO, "La Unesco y la Educación en América Latina y El Caribe", Op Cit, pág 78.

${ }^{3}$. Nos inclinamos a pensar que esta connotación de sociedad libre debe verse dentro de la coyuntura postguerra mundial, época en que fue redactado el Pacto y sobre todo dentro de un período denominado como "Guerra Fría". Con el advenimiento del bloque socialista encabezado por la potencia de la Unión Soviética y sus aliados por un lado, y el bloque del oeste cuyo país rector lo fue Estados Unidos y el bloque de Europa occidental, se suscita un enfrentamiento en todos los órdenes: ideológico/económico/político etc.

4 . "En pocas palabras, esta doctrina no significa otra cosa que legitimar una acción judicial indiscriminada sobre aquellos niños y adolescentes en situación de dificultad. Definido un "menor" en situación irregular (...) se exorcizan las deficiencias de las políticas sociales, optándose por "soluciones" de naturaleza individual que privilegian la institucionalización o la adopción" García Méndez, Emilio, "Infancia y Derechos Humanos", en "Estudios Básicos de Derechos Humanos", Vol II, Op Cit, pág 298.

${ }^{5}$. La citada normativa nos enuncia que: "1. Los Estados Partes convienen en que la educación del niño deberá estar encaminada a:

a) Desarrollar la personalidad, las aptitudes y la capacidad mental y física del niño hasta el máximo de sus posibilidades;

b) Inculcar al niño el respeto de los derechos humanos y las libertades fundamentales y de los principios consagrados en la Carta de las Naciones Unidas;

c) Inculcar al niño el respeto de sus padres, de su propia identidad cultural, de su idioma y sus valores, de los valores nacionales del país en que vive, del país de que sea originario y de las civilizaciones distintas de la suya;

d) Preparar al niño para asumir una vida responsable en una sociedad libre, con espíritu de comprensión, paz, tolerancia, igualdad de los sexos y amistad entre todos los pueblos, grupos étnicos, nacionales y religiosos y personas de origen indígena;

e) Inculcar al niño el respeto del medio ambiente natural". 
${ }^{6}$. Al respecto nos dice el párrafo segundo de esta observación General, lo siguiente: "La educación a que tiene derecho todo niño es aquella que se concibe para prepararlo para la vida cotidiana, fortalecer su capacidad de disfrutar de todos los derechos humanos y fomentar una cultura en la que prevalezcan unos valores de derechos humanos adecuados. El objetivo es habilitar al niño desarrollando sus aptitudes, su aprendizaje y otras capacidades, su dignidad humana, autoestima y confianza en sí mismo. En este contexto la "educación" es más que una escolarización oficial y engloba un amplio espectro de experiencias vitales y procesos de aprendizaje que permiten al niño, ya sea de manera individual o colectiva, desarrollar su personalidad, dotes y aptitudes y llevar una vida plena y satisfactoria en el seno de la sociedad".

7. Siguiendo con un autor como Segura, tenemos que él mismo establece otros criterios distintivos, tratándose de un órgano unipersonal como el que nos ocupa: "Representante Especial: es la persona nombrada por el Secretario General de Naciones Unidas, con el mandato de realizar un estudio a fondo sobre la situación de los derechos humanos en un país determinado, su Informe debe presentar recomendaciones sobre las medidas que se deben adoptar. Enviado Especial: es la persona nombrada por el Secretario General de Naciones Unidas, con el mandato de realizar un estudio sobre la situación de derechos humanos en un país determinado con la mayor discreción y objetividad posible. Su Informe debe tomar en cuenta todo material e información que el Gobierno concernido tenga a bien suministrar. Asimismo, el Informe debe ser presentado a la Comisión con la suficiente antelación, para que el Gobierno concernido presente sus observaciones por escrito., Op Cit, pág 328. Sin embargo, para la propia Organización de las Naciones Unidas, dispone que "la Comisión les da distintos nombres, como relator especial, experto independiente, representante del Secretario General o representante de la Comisión. Esos títulos no equivalen a una jerarquía ni son indicativos de las facultades concedidas a los expertos. Sencillamente, son la consecuencia de negociaciones políticas. Lo más importante es el mandato del experto como está formulado en las resoluciones de la Comisión de Derechos Humanos." Organización de las Naciones Unidas (ONU), "Diecisiete preguntas frecuentes acerca de los Relatores Especiales de las Naciones Unidas: Folleto Informativo No 27", Naciones Unidas, Ginebra, 1994, p. 10.

8 . Entre otros documentos podemos mencionar los siguientes: "Informe de la Relatora Especial sobre el derecho a la educación" (E/CN.4/2003/9/Add.2 del 2/5/2003); "El derecho a la educación - Informe de la Relatora Especial" (E/CN.4/2004/G/16 del 12/11/2003); "Informe presentado por el Relatora Especial sobre el derecho a la educación" (E/CN.4/2004/45 del 15/1/2004); "Informe del Sr. Vernor Muñoz Villalobos, Relator Especial sobre el derecho a la educación" (E/CN.4/2005/50 del 17/12/2004); "Informe del Relator Especial sobre el derecho a la educación, V. Muñoz Villalobos - El derecho a la educación de las niñas" (E/CN.4/2006/45 del 8/2/2006); "Informe del Relator Especial sobre el derecho a la educación, Vernor Muñoz Villalobos - Nota preliminar sobre la misión Marruecos" (A/HRC/4/29/Add.2 del 7/2/2007); "El derecho a la educación de las personas con discapacidades Informe del Relator Especial sobre el derecho a la educación, Vernor Muñoz" (A/HRC/4/29 del 19/2/2007); "Informe del Relator Especial sobre el derecho a la educación, Vernor Muñoz - Misión a Alemania" (A/HRC/4/29/Add.3) del 9/3/2007).

9. El Convenio de Convalidación de Estudios, Títulos y Diplomas de Educación Superior en los Estados Árabes, París, 22 de diciembre de 1978; el Convenio de Convalidación de Estudios, Títulos y Diplomas relativos a la Educación Superior en los Estados de la Región Europea, París, 21 de diciembre de 1979; el Convenio Regional de Convalidación de Estudios y Certificados, Diplomas, Grados y otros Títulos de Educación Superior en los Estados de África, Arusha, 5 de diciembre de 1981; El Convenio Regional de Convalidación de Estudios, Títulos y Diplomas de Educación Superior en Asia y el Pacífico, Bangkok, 16 de diciembre de 1983; la Convención sobre la Enseñanza Técnica y Profesional, París, 10 de noviembre de 1989; el Convenio sobre Reconocimiento de Cualificaciones relativas a la Educación Superior, Lisboa, 11 de abril de 1997. 
10 . Sobre el derecho al desarrollo debemos decir que "El derecho al desarrollo es un derecho humano inalienable en virtud del cual todo ser humano y todos los pueblos están facultados para participar en un desarrollo económico, social, cultural y político en el que puedan realizarse plenamente todos los derechos humanos y libertades fundamentales, a contribuir a ese desarrollo y a disfrutar de él" (Artículo primero de la Declaración sobre el Derecho al Desarrollo, adoptada por la Asamblea General de las Naciones Unidas el 4 de diciembre de 1986, con 146 votos a favor, uno en contra [EE.UU.] y ocho abstenciones). En este sentido, el desarrollo es un derecho humano que engloba el conjunto de los derechos humanos y pone de manifiesto la universalidad, interdependencia e indivisibilidad de dichos derechos, tal y como afirma la Declaración y Programa de Acción de Viena de 1993, fruto de la Conferencia Mundial de Derechos Humanos celebrada en dicha ciudad. Esta interpretación está en consonancia con lo dispuesto en los preámbulos de los Pactos Internacionales de los Derechos Económicos, Sociales y Culturales y de los Derechos Civiles y Políticos, adoptados en el marco de las Naciones Unidas en 1966, cuando se afirma lo siguiente:

"que, con arreglo a la Declaración Universal de Derechos Humanos, no puede realizarse el ideal del ser humano libre, en el disfrute de las libertades civiles y políticas y liberado del temor y de la miseria, a menos que se creen condiciones que permitan a cada persona gozar de sus derechos civiles y políticos, tanto como de sus derechos económicos, sociales y culturales".

Entre los objetivos de un derecho al desarrollo así concebido figura el mejorar el bienestar, la dignidad y la calidad de vida de todos los seres humanos, así como lograr una mayor igualdad económica y social, atendiendo especialmente a las necesidades de los individuos y grupos más vulnerables, y respetando la diversidad cultural. Para ello, debe erradicarse la pobreza, en tanto que objetivo primordial, y todos los Estados deben ratificar todos los tratados relativos a los derechos humanos sin reservas. Asimismo, los poderes públicos y privados deben ser controlables y fiscalizables por medios democráticos y deben rendir cuentas de sus actividades de manera transparente, de modo que pueda verificarse si se han ajustado o no a la ley, facilitando así la lucha contra la corrupción y la criminalidad. También puede considerarse como objetivo del desarrollo el logro de una paz justa en la que se respeten y protejan todos los derechos humanos para todos, pues de lo contrario sería una paz aparente que oculta una situación de opresión y violencia ejercida desde los poderes dominantes. Ésta es la mejor garantía de la seguridad para todos, a la cual debe unirse un desarme progresivo que disminuya la capacidad de amenazar y destruir, y que libere recursos económicos y humanos para actividades pacíficas. Además, el desarrollo debe ser sostenible, es decir, las generaciones futuras deberían heredar y disfrutar de nuestro planeta en las mismas condiciones que las generaciones presentes y, si es posible, aún mejor y más equitativamente.

11. Al respecto JACQUES DELORS, relator de una Comisión de la UNESCO, pondera la anterior situación de la siguiente manera: "Evidentemente, nuestra Comisión suscribe esas conclusiones, que coinciden con sus propias concepciones acerca de la finalidad de la educación y que no pueden por menos que afianzar su defensa de una cooperación internacional basada en la solidaridad y la colaboración en pie de igualdad. Aunque no conviene abusar de los objetivos cuantitativos, considera que, habida cuenta de la contribución específica de la educación al desarrollo social, se debería consagrar a aquella un porcentaje significativo de la ayuda pública para el desarrollo, que se podría fijar, en enlace con la acción de las organizaciones internacionales, en un cuarto de la ayuda global, que, por otra parte, es menester aumentar", UNESCO, La educación encierra un tesoro, Informe a la Unesco de la Comisión Internacional sobre la educación para el siglo XXI, preparado por Jacques Delors, Ediciones Unesco, Madrid, 1996, p. 206. 